\section{Does pain acceptance predict physical and psychological outcomes in cancer outpatients with pain?}

\section{Evangelia Protopapa, ${ }^{1}$ Victoria Senior ${ }^{2}$ \\ 1Surgery Unit, UCL Institute of Child \\ Health, London; ${ }^{2}$ Department of \\ Psychology, Faculty of Arts and Human Sciences, University of Surrey, Guildford, Surrey, UK}

\section{Abstract}

Pain acceptance has been associated with improved physical and psychosocial well-being in chronic non-malignant pain patients. However, its effects are unclear in cancer outpatients with pain. Our aim was to determine whether pain acceptance predicts reduced pain, pain interference with function, anxiety, and depression in cancer outpatients. We recruited 116 outpatients from a tertiary oncology center, with various types of cancer and pain levels. Patients completed the Brief Pain Inventory, the Hospital Anxiety and Depression Scale and the Chronic Pain Acceptance Questionnaire, the latter of which comprises activity engagement and pain willingness. We carried out multiple regression analyses, adjusting for patient characteristics and outcomes. Activity engagement and pain willingness significantly predicted pain interference with function $(\mathrm{P}=0.033$ and $\mathrm{P}=0.041$ respectively). However, only activity engagement predicted anxiety $(\mathrm{P}=0.001)$ and depression $(\mathrm{P}<0.001)$. These findings support the beneficial role of pain acceptance in patients' functional adaptation to cancer-related pain. Activity engagement in particular, shows promise in fostering psychological well-being. Further studies could confirm its role in reducing anxiety and depression in cancer patients with pain and whether it should be included in cancer pain management interventions.

\section{Introduction}

Aspects of cancer pain, such as increasing intensity and duration, have been linked to diminished quality of life, poor functioning and psychological distress, regardless of differences in measurement and type of patients. .-3 $^{-3}$ Pain acceptance could help cancer patients adapt to pain, since it has proven valuable in determining physical and emotional adjust- ment to chronic non-malignant pain. Pain acceptance refers to the continuation of activities despite experiencing pain, as well as the willingness to accept the presence of pain in order to discontinue futile attempts to control it and live a satisfying life. ${ }^{4}$ Acceptance has been associated with improved emotional, physical and social functioning in chronic pain sufferers. ${ }^{5,6}$ However, several studies have found no significant association between acceptance and pain intensity or physical functioning. ${ }^{7-9}$

Similarities in pain, activity and emotional distress between cancer and chronic non-cancer patients provide ground for exploration of the impact of the psychological therapeutic construct of acceptance within the context of cancer pain. To our knowledge, only one quantitative study has investigated pain acceptance in a cancer population. Gauthier et al. ${ }^{10}$ reported an association between pain acceptance and psychological well-being in patients with advanced cancer, but no association with pain or physical function. This finding has important implications, especially given that cancer patients frequently experience co-morbid pain and depression, ${ }^{2}$ two factors that react to one another and share common biological pathways. 11 The neurotransmitter imbalance occurring in depression is associated with greater sensitivity to pain and changes in pain perception. ${ }^{11,12}$ However, the direction of causality between pain and depression remains unspecified, 13 and it is possible that activity restriction may mediate the paindepression relationship. ${ }^{14-16}$ Additionally, evidence of the association between cancer pain and anxiety is limited; it is unclear whether anxiety exists due to variables occurring mainly in outpatient settings, such as waiting for procedures or test results. ${ }^{17,18}$ Studies have reported that patients' functional status and life disruption are critical in predicting abnormal anxiety levels. ${ }^{17,19}$

In light of these findings, we wished to further explore the effect of acceptance on physical and psychological well-being. Our aim was to determine whether pain acceptance predicts pain, pain-related functional interference, anxiety and depression in cancer outpatients.

\section{Materials and Methods}

Ethics approval was obtained from the University of Surrey Faculty of Arts and Human Sciences Ethics Committee and the Cyprus Bioethics Committee. Participants were consecutive outpatients at the day care center of the Bank of Cyprus Oncology Centre (BOCOC) in Cyprus, attending for chemotherapy and maintenance drug administration or doctor appointments. Eligible participants were over
Correspondence: Evangelia Protopapa, UCL Institute of Child Health, 30 Guildford Street, WC1N 1EH London, UK.

Tel. +44.020.7905.2134 - Fax: +44.020 .7404 .6181$

E-mail: e.protopapa@ucl.ac.uk

Key words: cancer, pain, acceptance, anxiety, depression.

Conflict of interests: the authors report no conflict of interests.

Contributions: EP, conception and design, acquisition, analysis and interpretation of data; article drafting and reviewing; VS, interpretation of data, article reviewing.

Acknowledgements: we would like to thank staff members at the Bank of Cyprus Oncology Centre who contributed by facilitating this research project. Special thanks to the participants for dedicating their time and effort.

Funding and conference presentation: this work was granted the Best of Young Investigators Award by the Cyprus Anti-Cancer Society in 2011. Part of it was presented at the Cyprus AntiCancer Society International Oncology Symposium (2011) and at the Multinational Association of Supportive Care in Cancer (MASCC) International Symposium (2011), under the Best of Young Investigators category. No funding.

Received for publication: 30 March 2013.

Revision received: 29 May 2013.

Accepted for publication: 2 June 2013.

This work is licensed under a Creative Commons Attribution NonCommercial 3.0 License (CC BYNC 3.0).

(C) Copyright E. Protopapa and V. Senior, 2013 Licensee PAGEPress, Italy

Health Psychology Research 2013; 1:e35

doi:10.4082/hpr.2013.e35

18 years of age, with any type of cancer and any level of cancer pain.

We recruited a sample of 145 consecutive cancer outpatients at the day care center in August 2010, of which 4 (3\%) were excluded due to incomplete responses, and 35 (24\%) were excluded because they experienced no cancer-related pain. Outpatients gave their informed consent, completed the questionnaires and returned them to the researcher (EP). After completion of the questionnaires, the researcher debriefed participants about the purpose of the study and the assessment measures used.

All assessment measures and forms were translated from English to Greek, and verified for grammar and comprehension. An independent translator then translated the forms and questionnaires back from Greek to English. There were virtually no differences 
between the original versions and the back translation. Participants were given either English or Greek questionnaires depending on the language they felt most comfortable with.

\section{Measures}

\section{Demographic and medical factors}

Demographic variables recorded for each participant included age, sex, family situation, educational level, work status and nationality. Reported medical factors included disease and treatment information such as primary cancer site, presence of metastasis, illness duration, pain location, cancer treatment and pain treatment. The level of pain treatment was coded according to the World Health Organization (WHO) analgesic ladder.20 Therefore, pain treatment was coded as none, Paracetamol/ NSAIDs, weak opioids and strong opioids. We also dichotomised pain treatment as treatment received or not.

\section{Pain assessment}

The Brief Pain Inventory (BPI) ${ }^{21}$ was used to assess two main dimensions; pain severity (sensory dimension) and pain interference with several aspects of daily functioning (reactive dimension). The short-form version (BPISF) used in this study assesses worst and least pain in the past 24 hours, average pain, and pain experienced at the time of questionnaire completion on an 11-point rating scale (0-10) with the anchors no pain and pain as bad as you can imagine. In addition, pain interference with general activity, mood, walking ability, normal work, relations with others, sleep and life enjoyment is rated on an 11-point rating scale with the anchors does not interfere and completely interferes. Scores of the 4 items measuring worst, least, average and current pain are added-up and divided by the number of items in order to calculate total pain severity. The scores of the 7 interference items are also added up and divided by the number of items to calculate total pain interference. Total pain severity and total pain interference scores range from 0-10. Cronbach's alpha for the Severity and Interference scales was 0.88 and 0.93 respectively.

\section{Psychological distress}

Anxiety and depression levels were measured with the Hospital Anxiety and Depression scale, a screening tool with the purpose of identifying co-morbid anxiety and depression in populations found in medical settings. ${ }^{22}$ The HAD scale focuses on nonsomatic symptoms of anxiety and depression, such as autonomic anxiety and unhedonia. The scale consists of 14 items; 7 items for the anxiety subscale and 7 for the depression subscale. Each item is scored on a 4-point scale ranging from $0-3$, yielding a total score of 0-21 for each subscale. Cronbach's alpha for the Anxiety and Depression scales was 0.85 and 0.79 respectively.

\section{Acceptance}

The Chronic Pain Acceptance Questionnaire $(\mathrm{CPAQ})^{23}$ measures the degree to which the patient accepts pain as a part of daily life and carries on with general activities as normal. The revised 20-item version was used in the present study. 24 The CPAQ questionnaire consists of two subscales; Activity Engagement and Pain Willingness. Activity Engagement refers to the continuation of activities as normal even if experiencing pain, whereas Pain Willingness refers to the individual's willingness, as opposed to reluctance, to experience pain without futile attempts to control it. Each item of the questionnaire is rated on a 7-point rating scale ranging from $0-6$, depending on the extent to which each statement applies to the participant (e.g. $0=$ never true and $6=$ always true). Scores for Activity Engagement range from 0 to 66 and for Pain Willingness from 0 to 54. Cronbach's alpha for the Activity Engagement and Pain Willingness subscales was 0.83 and 0.84 respectively.

\section{Statistical analysis}

Data were screened for accuracy, missing values and normal distribution. They were not normally distributed, therefore we carried out non parametric univariate analyses.

Demographic, disease and treatment characteristics were collected to describe the sample. Univariate analyses such as MannWhitney U, Kruskall-Wallis H and Spearman's correlations were carried out where appropriate to assess the relationship between sample characteristics and assessment measures. Patient characteristics and outcome variables that were significantly associated with other patient outcomes and the acceptance subscales at 0.05 in univariate analyses were included in the multiple regression model. Multicollinearity was tested by examining values of Tolerance and Variance Inflation Factor (VIF). Data were analyzed using SPSS (Statistical Package for the Social Sciences; Chicago, IL, USA) v.21.0.1.

\section{Results}

\section{Patient characteristics}

Of the 116 participants included in the study (Table 1) the majority were female (76.7\%), married (83.6\%) and of Greek Cypriot nationality (89.7\%). Ages ranged from 18 to 79 years $(\mathrm{M}=56.23, \mathrm{SD}=12.26)$.
Participants' medical characteristics revealed that breast cancer was the most common diagnosis (52.6\%) and that 43 (37.1\%) patients had metastatic disease. Cancer duration ranged from 1 month to 22 years $(\mathrm{M}=39.21$ months, $\mathrm{SD}=52.91)$. The most frequently reported pain locations were the chest (31.9\%), abdomen (29.3\%) and back (21.6\%). Most participants were receiving cancer treatment (81.9\%) and Paracetamol/ Non-steroidal anti-inflammatory drugs (38.8\%), while $52.5 \%$ of patients reported receiving no pain medication despite indicating that they experienced pain. Pain treatment was classified according to guidelines for cancer pain relief by the World Health Organization. ${ }^{20}$

\section{Univariate analyses}

\section{Acceptance}

Univariate non parametric analyses were carried out in order to detect any significant associations between patient characteristics and acceptance subscales. Participants who were working had significantly higher activity engagement scores $(\mathrm{P}=0.027)$ compared to those not working. Patients' primary cancer site influenced their activity engagement scores $(\mathrm{P}=0.009)$. Gynecological/genitourinary cancers had the lowest activity engagement scores $(29.56 \pm 15.45)$. Pain in the abdomen was associated with lower activity engagement $(\mathrm{P}=0.044)$. Patients receiving pain treatment had significantly lower activity engagement $(\mathrm{P}=0.005)$. Pain willingness was not associated with patient characteristics.

\section{Patient outcomes}

Further univariate analyses identified associations between patient characteristics and outcome measures.

A higher education level was associated with lower pain $(\mathrm{r}=-0.228, \mathrm{P}=0.014)$, anxiety $(\mathrm{r}=-0.287, \mathrm{P}=0.002)$ and depression $(\mathrm{R}=-$ $0.189, \mathrm{P}=0.042$ ) scores. Participants who were working had significantly lower anxiety $(\mathrm{P}=0.044)$ and depression scores $(\mathrm{P}=0.019)$ compared to those not working. Patients' primary cancer site influenced their pain interference $(\mathrm{P}=0.008)$, depression $(\mathrm{P}=0.004)$ and activity engagement scores $(\mathrm{P}=0.009)$. Gynecological/genitourinary cancers had the highest mean pain interference scores (5.82 \pm 2.68$)$, while lung cancer patients had the highest depression scores $(12.00 \pm 3.94)$. Back pain was associated with higher pain severity $(\mathrm{P}=0.45)$, as was pain in the abdomen $(\mathrm{P}=0.031)$. Patients with $2-4$ pain sites had higher pain severity $(\mathrm{P}=0.41)$ and pain interference scores $(\mathrm{P}=0.42)$. Patients receiving pain treatment had significantly 
higher scores of pain severity $(\mathrm{P}=0.014)$, pain interference $(\mathrm{P}=0.013)$, anxiety $(\mathrm{P}<0.001)$, and depression $(\mathrm{P}<0.001)$.

\section{Bivariate associations between pain acceptance and physical and psy- chological outcomes}

Spearman's correlations (Table 2) revealed that activity engagement was significantly correlated with pain severity, pain interference, anxiety and depression. Pain willingness was weakly correlated with pain severity and pain interference.

\section{Linear multiple regression: role of acceptance subscales in predicting outcomes}

Multiple regression was used to determine the extent to which Activity Engagement and Pain Willingness predict physical and psychological outcomes. Patient demographic and medical characteristics significant at $\mathrm{P}<0.05$ were included in the model when associated with the outcome variable, or both the predictor and outcome. Neither acceptance subscale predicted pain severity.

Activity engagement and pain willingness, together with gynecological/genitourinary cancer, pain severity and depression accounted for $59 \%$ of the variance in pain interference with function, $[F(8,107)=18.94, P<0.001]$ (Table 3 ).

Activity engagement, in addition to education, pain treatment and interference, accounted for $33 \%$ of the variance in anxiety $[\mathrm{F}(6,109)=8.89, \mathrm{P}<0.001]$ (Table 4).

Activity engagement, together with lung cancer site, pain treatment and pain interference accounted for $56 \%$ of the variance in depression scores $[\mathrm{F}(7,108)=19.71, \mathrm{P}<0.001]$ (Table 5).

\section{Discussion}

The aim of the present study was to investigate the role of pain acceptance in physical and functional outcomes (pain and its interference with daily life) and psychological outcomes (anxiety and depression) in a sample of outpatients with cancer pain. The activity engagement subscale of the acceptance measure predicted pain interference, anxiety, and depression. The pain willingness subscale predicted only pain interference and not the psychological outcomes of anxiety and depression. Neither acceptance subscale played a role in predicting pain severity. Our findings replicate and extend those of the only previous study we are aware of investigating the role of acceptance in a cancer population. ${ }^{10} \mathrm{We}$ replicate the finding that greater activity engage- ment predicts better psychological outcomes. We extend this previous research with our finding that both pain willingness and activity engagement seem to play a role in the extent to which pain interferes with everyday functioning. It should be noted that, outside of the cancer literature, most acceptance studies

have found associations between physical and psychosocial functioning with both acceptance subscales and with overall acceptance. $6,8,9,25$

Thus, our findings support the growing consensus that acceptance is associated with improved emotional, physical, and social functioning in the wider pain literature.5,9 This is

Table 1. Sample characteristics $(\mathrm{N}=116)$.

\begin{tabular}{|c|c|}
\hline & Mean \pm SD (frequency) \\
\hline Age (range: 18-79) & $56.23 \pm 12.26$ \\
\hline \multicolumn{2}{|l|}{ Sex } \\
\hline Male & $27(23.3 \%)$ \\
\hline Female & $89(76.7 \%)$ \\
\hline $\begin{array}{l}\text { Ethnicity } \\
\text { Greek/Greek-Cypriot } \\
\text { Other }\end{array}$ & $\begin{array}{c}102(87.9 \%) \\
14(12.1 \%)\end{array}$ \\
\hline $\begin{array}{l}\text { Education } \\
\text { Primary school } \\
\text { High school } \\
\text { College/university }\end{array}$ & $\begin{array}{l}28(24.1 \%) \\
54(46.6 \%) \\
34(29.3 \%)\end{array}$ \\
\hline $\begin{array}{l}\text { Work status } \\
\text { Employed (full/part-time) } \\
\text { Not working (unemployed/homemaker/retired/student) } \\
\text { Not working due to illness (on sick leave/medical retirement) }\end{array}$ & $\begin{array}{l}40(34.5 \%) \\
51(44.0 \%) \\
25(21.6 \%)\end{array}$ \\
\hline $\begin{array}{l}\text { Marital status } \\
\text { Married/co-habiting } \\
\text { Single/separated/widowed }\end{array}$ & $\begin{array}{l}97(83.6 \%) \\
19(16.4 \%)\end{array}$ \\
\hline $\begin{array}{l}\text { Primary cancer site } \\
\text { Breast } \\
\text { Gastrointestinal } \\
\text { Lung } \\
\text { Gynaecologic/genito-urinary } \\
\text { Other }\end{array}$ & $\begin{array}{c}61(52.6 \%) \\
24(20.7 \%) \\
9(7.8 \%) \\
11(9.5 \%) \\
11(9.5 \%)\end{array}$ \\
\hline $\begin{array}{l}\text { Cancer duration, months (range: 1-264) } \\
\text { Metastasis } \\
\text { No metastasis } \\
\text { Cancer treatment } \\
\text { No cancer treatment }\end{array}$ & $\begin{array}{l}39.21 \pm 52.91 \\
43(37.1 \%) \\
73(62.9 \%) \\
96(82.8 \%) \\
20(17.2 \%)\end{array}$ \\
\hline $\begin{array}{l}\text { Cancer treatment } \\
\text { Chemotherapy } \\
\text { Targeted therapy } \pm \text { chemotherapy } \\
\text { Radiotherapy } \pm \text { chemotherapy } \\
\text { No cancer treatment }\end{array}$ & $\begin{array}{c}70(60.3 \%) \\
21(18.1 \%) \\
4(3.4 \%) \\
21(18.1 \%)\end{array}$ \\
\hline $\begin{array}{l}\text { Pain site (multi-response variable) } \\
\text { Head and neck } \\
\text { Chest } \\
\text { Back } \\
\text { Abdomen } \\
\text { Pelvic region } \\
\text { Upper limbs } \\
\text { Lower limbs } \\
\text { Bones } \\
\text { Unknown }\end{array}$ & $\begin{array}{c}12(10.3 \%) \\
37(31.9 \%) \\
25(21.6 \% \\
34(29.3 \%) \\
6(5.2 \%) \\
12(10.3 \%) \\
20(17.2 \%) \\
7(6.0 \%) \\
5(4.3 \%)\end{array}$ \\
\hline $\begin{array}{l}\text { No. of reported pain sites } \\
1 \\
2-4\end{array}$ & $\begin{array}{l}76(65.5 \%) \\
35(30.2 \%)\end{array}$ \\
\hline $\begin{array}{l}\text { Pain treatment (highest WHO class of analgesics reported) } \\
\text { None } \\
\text { Paracetamol/NSAIDs } \\
\text { Weak opioids } \\
\text { Strong opioids }\end{array}$ & $\begin{array}{c}59(50.9 \%) \\
45(38.8 \%) \\
2(1.7 \%) \\
10(8.6 \%)\end{array}$ \\
\hline Pain treatment & $57(49.1 \%)$ \\
\hline No pain treatment & $59(50.9 \%)$ \\
\hline
\end{tabular}


Table 2. Descriptive statistics and correlation matrix of measures.

\begin{tabular}{|c|c|c|c|c|c|c|}
\hline & Mean \pm SD & $\begin{array}{l}\text { BPI - } \\
\text { severity }\end{array}$ & $\begin{array}{c}\text { BPI - } \\
\text { interference }\end{array}$ & $\begin{array}{l}\text { HADS- } \\
\text { anxiety }\end{array}$ & $\begin{array}{l}\text { HADS- } \\
\text { depression }\end{array}$ & $\begin{array}{l}\text { CPAQ- } \\
\text { activity engagement }\end{array}$ \\
\hline BPI severity & $3.33 \pm 1.83$ & & & & & \\
\hline BPI interference & $3.95 \pm 2.51$ & $\begin{array}{l}0.618^{*} \\
\mathrm{P}<0.001\end{array}$ & & & & \\
\hline HADS - anxiety & $7.61 \pm 4.48$ & $\begin{array}{c}0.310^{*} \\
\mathrm{P}=0.001\end{array}$ & $\begin{array}{c}0.424^{*} \\
\mathrm{P}<0.001\end{array}$ & & & \\
\hline HADS - depression & $6.51 \pm 4.18$ & $\begin{array}{c}0.363^{*} \\
\mathrm{P}<0.001\end{array}$ & $\begin{array}{c}0.546^{*} \\
\mathrm{P}<0.001\end{array}$ & $\begin{array}{l}0.662^{*} \\
\mathrm{P}<0.001\end{array}$ & & \\
\hline CPAQ - activity engagement & $42.08 \pm 13.57$ & $\begin{array}{l}-0.252^{*} \\
\mathrm{P}=0.006\end{array}$ & $\begin{array}{l}-0.432^{*} \\
\mathrm{P}<0.001\end{array}$ & $\begin{array}{l}-0.483^{*} \\
\mathrm{P}<0.001\end{array}$ & $\begin{array}{l}-0.571^{*} \\
P<0.001\end{array}$ & \\
\hline CPAQ - pain willingness & $18.07 \pm 11.22$ & $\begin{array}{c}-0.182 \\
P=0.051\end{array}$ & $\begin{array}{l}-0.199 * * \\
\mathrm{P}=0.033\end{array}$ & $\begin{array}{c}-0.018 \\
P=0.850\end{array}$ & $\begin{array}{c}-0.128 \\
P=0.171\end{array}$ & $\begin{array}{c}-0.130 \\
P=0.166\end{array}$ \\
\hline
\end{tabular}

BPI, Brief Pain Inventory; HADS-A, Hospital Anxiety and Depression Scale-Anxiety; HADS-D, Hospital Anxiety and Depression Scale-Depression; CPAQ, Chronic Pain Acceptance Questionnaire. *Significant at 0.01 (two-tailed); **Significant at 0.05 (two-tailed).

of substantial interest given that acceptance appears to be a modifiable construct that is amenable to intervention. A recent systematic review and meta-analysis of acceptance-based interventions for the treatment of chronic pain found that acceptance-based interventions across different chronic pain populations improve both pain intensity and physical wellbeing, as well as depression, anxiety, and quality of life. ${ }^{26}$ The authors did not break down the analysis by acceptance subscales, but our findings suggest that focusing interventions on continuing activities as normal despite pain will be most useful for improving both physical and psychological outcomes, at least in cancer patients. Our findings also suggest that interventions which focus on being willing to experience pain without futile attempts to control it may also be useful for improving the extent to which pain interferes with everyday living, but possibly not for improving psychological wellbeing. Perhaps the willingness to experience pain is unrealistic in cancer patients, especially since cancer pain could signify tumor growth and disease progression. ${ }^{27}$ Most research concerning acceptance applies to chronic pain populations, and although the same physiological mechanisms may be involved in both cancer pain and non-malignant pain, ${ }^{28}$ it cannot be ignored that tumor-related factors or individual response to cancer treatment are likely to affect cancer patients' physical and psychosocial functioning. The fact that the severity of cancer pain was not associated with acceptance measures in multivariate analyses also, perhaps, suggests that acceptance-based interventions may be effective whatever level of cancer pain is being experienced. However, this hypothesis awaits testing.

Activity engagement, but not pain willingness, was also associated with certain patient characteristics in the present study. Participants who were working reported higher activity engagement, as in studies on nonmalignant pain.4,6 It may be that a willingness
Table 3. Multiple regression with pain interference as the outcome variable.

\begin{tabular}{llcccc}
\hline $\begin{array}{l}\text { Pain interference } \\
\text { Predictors }\end{array}$ & B & SE & Beta & P & $95 \%$ CI for B \\
Constant & 2.18 & 1.04 & & 0.039 & $0.11,4.25$ \\
Gynecological/genitourinary cancer & 1.39 & 0.56 & 0.16 & $0.014^{*}$ & $0.28,2.49$ \\
\hline No. of pain sites $(\geq 2)$ & 0.40 & 0.24 & 0.11 & 0.097 & $-0.07,0.87$ \\
Pain treatment & -0.10 & 0.35 & -0.02 & 0.782 & $-0.79,0.60$ \\
\hline BPI - severity & 0.55 & 0.10 & 0.40 & $0.00^{* *}$ & $0.36,0.74$ \\
HADS - anxiety & 0.02 & 0.05 & 0.04 & 0.673 & $-0.08,0.12$ \\
\hline HADS - depression & 0.16 & 0.06 & 0.27 & $0.007^{* *}$ & $0.04,0.28$ \\
CPAQ - activity engagement & -0.03 & 0.02 & -0.17 & $0.033^{*}$ & $-0.06,-0.00$ \\
\hline CPAQ - pain willingness & -0.03 & 0.02 & -0.14 & $0.041^{*}$ & $-0.06,-0.00$ \\
\hline
\end{tabular}

*Significant at $0.05 ; *$ Significant at 0.01 .

Table 4. Multiple regression with anxiety as the outcome variable.

\begin{tabular}{lccccc} 
Predictors & B & SE & Beta & P & $95 \%$ CI for B \\
Constant & 11.75 & 2.7 & & 0.000 & $6.40,17.10$ \\
Education & -1.07 & 0.52 & -0.18 & $0.042^{*}$ & $-2.1,-0.04$ \\
\hline Work status & -0.14 & 0.81 & -0.01 & 0.867 & $-1.72,1.45$ \\
Pain treatment & 1.49 & 0.73 & 0.17 & $0.044^{*}$ & $0.04,2.93$ \\
\hline BPI - severity & -0.04 & 0.25 & -0.02 & 0.882 & $-0.53,0.45$ \\
BPI - interference & 0.44 & 0.19 & 0.25 & $0.023^{*}$ & $0.06,0.82$ \\
\hline CPAQ - activity engagement & -0.1 & 0.03 & -0.30 & $0.001^{* *}$ & $-0.16,-0.04$ \\
\hline
\end{tabular}

*Significant at $0.05 ; * *$ Significant at 0.01 .

Table 5. Multiple regression with depression as the outcome variable.

\begin{tabular}{lccccc} 
Predictors & B & SE & Beta & P & $95 \%$ CI for B \\
Constant & 7.54 & 2.10 & & 0.000 & $3.38,11.71$ \\
Education & -0.43 & 0.40 & -0.07 & 0.289 & $-1.21,0.37$ \\
\hline Work status & 0.51 & 0.61 & 0.06 & 0.409 & $-0.71,1.73$ \\
Lung cancer & 3.30 & 1.04 & 0.21 & $0.002^{*}$ & $1.24,5.36$ \\
\hline Pain treatment & 1.70 & 0.56 & 0.20 & $0.003^{*}$ & $0.59,2.81$ \\
BPI - severity & -0.06 & 0.19 & -0.03 & 0.760 & $-0.43,0.32$ \\
\hline BPI - interference & 0.57 & 0.15 & 0.34 & $0.000^{*}$ & $0.28,0.86$ \\
CPAQ - activity engagement & -0.10 & 0.02 & -0.32 & $0.000^{*}$ & $-0.14,-0.05$ \\
\hline
\end{tabular}

*Significant at 0.01 
to continue as normal with activities helps people with a cancer diagnosis to retain their work. Alternatively, it may be that continuing to work despite the cancer diagnosis leads to improvements in activity engagement. Activity engagement also varied by cancer site and pain site, with gynecological/genitourinary cancers and pain in the abdomen being associated with the lowest activity engagement scores. The reason for these findings is not known and needs to be replicated with a larger study focused primarily upon this research question. Additionally, participants in our study receiving pain treatment had lower activity engagement scores, whereas McCracken and Eccleston ${ }^{6}$ reported increased use of medication in patients with lower pain willingness. It is possible that attempts to control pain through medical means may sit uncomfortably alongside the notion of acceptance expressed as continuing engagement with normal activities despite pain. It would be interesting to see whether acceptance-based interventions are differentially effective depending on whether patients are also taking analgesics or not.

This study is not without limitations. The majority of participants were female, with breast cancer, aged 60-69, Greek Cypriot and married, therefore it may be difficult to generalize findings. However, results are mainly consistent with studies in diverse cultural populations despite variability in assessment measures, suggesting that cancer pain and psychological co-morbidity are universal factors. Due to the cross-sectional study design, data were collected at one point in time in the form of self-report measures, engendering the possibility of discrepancy between reported results and actual behavior. Despite this, patients' subjective perception of pain, distress and behavior were of primary research interest. Effects of fatigue, insomnia, apprehension about the diagnosis or medical visit and effects of pharmacological treatments may have possibly occurred at varying degrees during questionnaire completion. It is also difficult to assess psychological health especially when there is confusion between normal sadness due to physical illness and abnormal clinical depression. ${ }^{29}$ Depressive symptoms exist in a broad range, which may be complicated to assess while the patient's life is threatened or while they are tired, in pain and receiving cancer treatment. ${ }^{30}$ This aspect is controlled by the fact that the Hospital Anxiety and Depression scale rules out somatic symptoms of depression, or in this case somatic symptoms possibly resulting from cancer and its treatment. Results of this study and previous cancer pain studies are similar to chronic pain research findings which verify that non-malignant pain has similar associations with mental health in both inpatient and outpatient settings. $11,31,32$

\section{Conclusions}

The present study provides additional evidence for the role of acceptance in adaptation to pain interference with function and psychological distress in cancer outpatients. Prospective studies could include both outpatients and hospitalized patients to detect any significant differences in levels of pain and distress between the two patient categories, ${ }^{33}$ and how these are influenced by acceptance. Further prospective confirmation of which components of pain acceptance predict cancer patient outcomes would be a step towards establishing their potential use in acceptancebased and cognitive-behavioral interventions for cancer pain. Special focus could be applied to the potential role of Activity Engagement in mediating pain interference, anxiety, and depression.

\section{References}

1. Glover J, Dibble SL, Dodd MJ, Miaskowski C. Mood states of oncology outpatients does pain make a difference. J Pain Symptom Manage 1995;10:120-8.

2. Laird BJA, Boyd AC, Colvin LA, Fallon MT. Are cancer pain and depression interdependent? A systematic review. PsychoOncology 2009;18:459-64.

3. Zaza C, Baine N. Cancer pain and psychosocial factors: a critical review of the literature. J Pain Symptom Manage 2002;24:526-42.

4. McCracken LM. Learning to live with the pain: acceptance of pain predicts adjustment in persons with chronic pain. Pain 1998;74:21-7.

5. Vowles KE, McCracken LA, Eccleston C. Patient functioning and catastrophizing in chronic pain: The mediating effects of acceptance. Health Psychology 2008;27: S136-43.

6. McCracken LM, Eccleston C. A prospective study of acceptance of pain and patient functioning with chronic pain. Pain 2005;118:164-9.

7. Nicholas MK, Asghari A. Investigating acceptance in adjustment to chronic pain: is acceptance broader than we thought? Pain 2006;124:269-79.

8. McCracken LM, Vowles KE, Eccleston C. Acceptance-based treatment for persons with complex, long standing chronic pain: a preliminary analysis of treatment outcome in comparison to a waiting phase. Behav Res Ther 2005;43:1335-46.

9. Viane I, Crombez G, Eccleston C, et al. Acceptance of pain is an independent predictor of mental well-being in patients with chronic pain: empirical evidence and reappraisal. Pain 2003;106:65-72.

10. Gauthier LR, Rodin G, Zimmermann C, et al. Acceptance of pain: a study in patients with advanced cancer. Pain 2009;143:14754.

11. Bair MJ, Robinson RL, Katon W, Kroenke K. Depression and pain comorbidity. A literature review. Arch Intern Med 2003;163:2433-45.

12. Aukst-Margetic B, Jakovljevic M, Margetic B, et al. Religiosity, depression and pain in patients with breast cancer. Gen Hosp Psychiatry 2005;27:250-5.

13. Jack L, Scott A, Colvin L, et al. Pain and depression in cancer patients: a longitudinal study. BMJ Supportive Palliative Care 2011;1:A11.

14. Badr H, Laurenceau JP, Schart L, et al. The daily impact of pain from metastatic breast cancer on spousal relationships: a dyadic electronic diary study. Pain 2010;151:64454.

15. Parmelee PA, Harralson TL, Smith LA, Schumacher HR. Necessary and discretionary activities in knee osteoarthritis: do they mediate the pain-codepression relationship? Pain Med 2007;8:449-61.

16. Williamson GM, Schulz R. Activity restriction mediates the association between pain and depressed affect - a study of younger and older adult cancer-patients. Psychol Aging 1995;10:369-78.

17. Chen ML, Chang HK, Yeh CH. Anxiety and depression in Taiwanese cancer patients with and without pain. J Adv Nurs 2000;32:944-51.

18. Velikova G, Selby PJ, Snaith PR, Kirby PG. The relationship of cancer pain to anxiety. Psychother Psychosom 1995;63:181-4.

19. Thielking P. Cancer pain and anxiety. Curr Pain Headache Rep 2003;7:249-61.

20. Stjernsward J. WHO cancer pain relief program. Cancer Surveys 1988;7:195-208.

21. Cleeland CS, Ryan KM. Pain assessment: global use of the Brief Pain Inventory. Ann Acad Med Singapore 1994;23:129-38.

22. Zigmond AS, Snaith RP. The Hospital Anxiety and Depression Scale. Acta Psychiatrica Scandinavica 1983;67:361-70.

23. Geiser DS. A comparison of acceptancefocused and control-focused psychological treatments in a chronic pain treatment center. Phd dissertation. University of Nevada, 1992.

24. McCracken LM, Vowles KE, Eccleston C. Acceptance of chronic pain: component analysis and a revised assessment method. Pain 2004;107:159-66.

25. McCracken LM, Zhao-O'Brien J. General psychological acceptance and chronic pain: there is more to accept than the pain itself. Eur J Pain 2010;14:170-5.

26. Veehof MM, Oskam MJ, Schreurs KMG, 
Bohlmeijer ET. Acceptance-based interventions for the treatment of chronic pain: a systematic review and meta-analysis. Pain 2011;152:533-42.

27. Portenoy RK, Kornblith AB, Wong G, et al. Pain in ovarian cancer patients. Prevalence, characteristics, and associated symptoms. Cancer 1994;74:907-15.

28. Turk DC. Remember the distinction between malignant and benign pain? Well, forget it. Clin J Pain 2002;18:75-6.
29. Bukberg J, Penman D, Holland JC. Depression in hospitalized cancerpatients. Psychosom Med 1984;46:199-212.

30. Massie MJ. Prevalence of depression in patients with cancer. J Natl Cancer Inst Monogr 2004;57-71.

31. Becker N, Bondegaard Thomsen A, Olsen AK, et al. Pain epidemiology and health related quality of life in chronic non-malignant pain patients referred to a Danish multidisciplinary pain center. Pain
1997;73:393-400.

32. Williams AC, Richardson PH, Nicholas MK et al. Inpatient vs. outpatient pain management: results of a randomised controlled trial. Pain 1996;66:13-22.

33. Aass N, Fosss SD, Dahl AA, Aloe TJ. Prevalence of anxiety and depression in cancer patients seen at the Norwegian Radium Hospital. Eur J Cancer 1997;33: 1597-604. 